\title{
ISOLATION OF BETA-ASARONE AND FORSKOLIN AND THEIR In Vivo ACTIVITY Against STRESS
}

\author{
Neha Tiwari ${ }^{1 *}$ and Pragnesh Patani ${ }^{2}$ \\ ${ }^{1}$ Department of Pharmaceutical Chemistry; ${ }^{2}$ Department of Pharmacology, A-One Pharmacy College, \\ Anasan-382330, Ahmedabad, Gujarat, India \\ *E-mail: neha_pharmaco@rediffmail.com \\ Tel.: +919924341133.
}

Received: Mar 20, 2019 / Revised: Apr 29, 2019 / Accepted: Apr 30, 2019

\begin{abstract}
Stress is known to result in impairment of learning and memory and precipitate several affective disorders including depression and anxiety. Drugs of natural origin are known to possess several effects on the central nervous system and are emerging as promising alternative. Beta-asarone is one of the main bioactive constituents in traditional Chinese medicine Acorus calamus. Forskolin, a labdane diterpene is the main active ingredient in the ayurvedic herb Coleus forskohlii (Labatiae) that has been used in India since ancient times. The present study was designed to evaluate the antistress activity of the isolated compounds. The compounds were isolated by normal phase column chromatography and the structures were elucidated by spectroscopic methods. Beta-asarone and Forskolin were tested using elevated plus maze (EPM) model and forced swimming test (FST) respectively in Swiss albino mice. Albino mice were treated with different doses of the extracts (50, 100 and $200 \mathrm{mg} / \mathrm{kg}$ orally) and behavior was observed on the EPM and FST. Results showed that isolated compounds Beta-asarone and Forskolin at the dose of $100 \mathrm{mg} / \mathrm{kg}$ markedly increased the average time spent in the open arms in EPM and the same compounds showed a significant decrease in the time spent immobile by mice in FST. These results provide support for the potential antistress activity.
\end{abstract}

Key words: Antistress, Beta-asarone, Forskolin, Elevated plus maze model, Forced swimming test.

\section{INTRODUCTION}

Stress is a common phenomenon that is experienced by every individual. When stress becomes extreme, it is harmful for the body and hence needs to be treated. Stress is involved in the pathogenesis of a variety of diseases including hypertension, peptic ulcer, immunodepression, reproductive dysfunction and behavior disorder (Singh et al 2009), behavioral disorders like anxiety due to involvement of the central nervous system (CNS), endocrine system and metabolic system. Drugs having antistress properties induce a state of non-specific resistance against stressful conditions. Drugs like benzodiazepines, certain
CNS stimulants such as amphetamines and caffeine as well as some anabolic steroids are routinely used by people to combat stress. The incidence of toxicity and dependence has limited the therapeutic usefulness of these drugs (Desai et al 2009).

Herbal formulations and medicinal plants have been in use for many years not only in Asian countries but also globally for human well-being as well as reported in literature for their biopotential (Dahiya et al 2019; Oloke et al 2017; Dahiya et al 2017; Senthil Kumar et al 2017; Viana et al 2017; Dahiya and Singh, 2017a; 2017b; 2017c). The herbal formulations claimed to enhance physical endurance, mental functions 
and non-specific resistance of the body and have been termed as adaptogens (Desai et al 2009). Various plants are being used in complementary and alternative medicines for management of stress (Gupta et al 2010). The potential utility of safer and cheaper herbal medicines as antistress agents have been reported as they can withstand stress without altering the physiological functions of the body. Herbal medicines are known to act synergistically in combination (Desai et al 2009).

Acorus calamus (Family: Araceae) is a popular traditional medicinal plant. In Ayurvedic medicine, it is used for the treatment of insomnia, neurosis, epilepsy, hysteria, loss of memory and many more diseases (Tiwari et al 2010). Beta-asarone (cis-2,4,5-trimethoxy-1- propenylbenzene) is a major active principle found in A. calamus (Shenvi et al 2011).

Coleus forskohlii is an important plant in Indian Ayurvedic medicine. It is the only source for Forskolin among the plant kingdom. Forskolin has a unique property of activating almost all hormone sensitive adenylate cyclase enzymes in a biological system. Forskolin is reported to be useful in the treatment of congestive heart failure, glaucoma, asthma and certain type of cancers. It is an important plant used against various disorders in indigenous systems of medicine such as anti-aging, antioxidant, as a remedy for heart, abdominal and respiratory disorders (Khatun et al 2011). The chemical structures of Beta-asarone and Forskolin are presented in Figure 1.
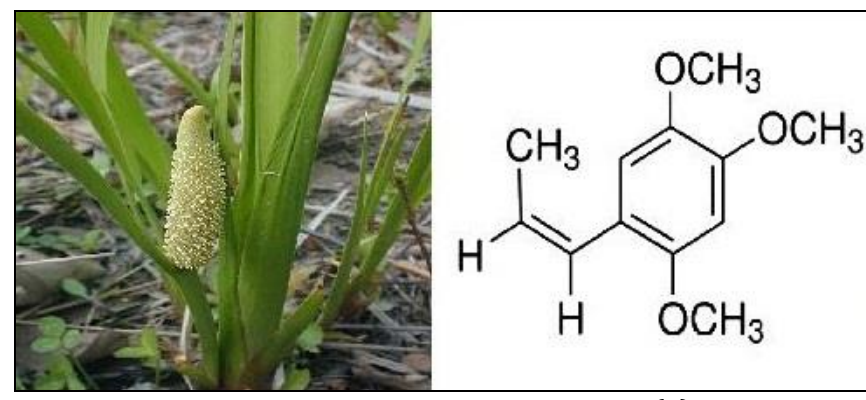

(a)

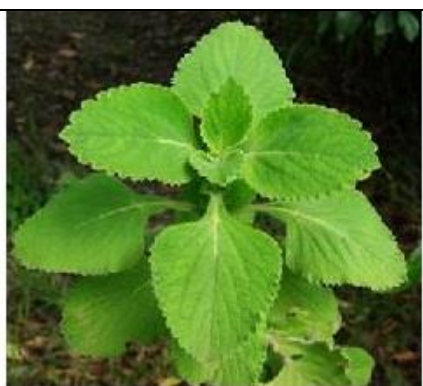

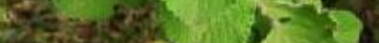

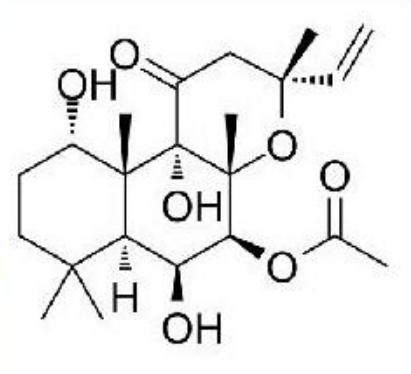

(b)

Fig. 1. Structures of (a) Beta-asarone (from A. calamus) and (b) Forskolin (from C. forskohlii)

\section{MATERIALS AND METHODS Plant material}

The rhizomes of Acorus calamus and Coleus forskohlii were collected from the High Altitude Plant Physiology Research Centre (HAPPRC), Srinagar, Uttarakhand, India in the month of march 2018 and were taxonomically authenticated by the Dr. Alok Lehri, Scientist E-1, Central Instrumental Facility, National Botanical Research Institute, Lucknow, India. The rhizomes were air dried for 20 days, crushed into coarse powder with a grinder and passed through 40-mesh sieve. They were stored in a well closed container separately.

\section{Isolation of compound 1 from rhizomes of A. calamus}

The powder rhizomes were dried in the dark at room temperature. Dried and powdered material (950 g) was taken in a round-bottom flask and was first defatted with petroleum ether twice. The marc was then extracted with ethanol:water (60:40) twice. After $48 \mathrm{~h}$, the extract was filtered. The filtrate was evaporated and the dark green crude extract was obtained with a yield approximately 270 g. The concentrated hydro-alcoholic extract (15 g) was subjected to silica gel column (60-120 mesh, $500 \mathrm{~g}$ ) and successively eluted with a stepwise gradient of chloroform / methanol $(100 / 0,95 / 5$, $90 / 10,75 / 25,50 / 50$, and $0 / 100, v / v$ ). Column fractions were analyzed by TLC (silica gel G), and fractions with a similar TLC pattern were pooled and concentrated.

The active 90/10 elutes which showed three compounds in TLC $\left(\mathrm{R}_{\mathrm{f}}: 0.56,0.63,0.73\right)$ was successively re-chromatographed on a silica gel column with using solvents (Toluene:ethyl acetate:chloroform / 6:2:2). Finally obtained fractions was (18-20) having single compound AC- 1 confirmed by TLC ( $n$-hexane: toluene: ethyl acetate / 1:1:0.1). The $\mathrm{R}_{\mathrm{f}}$ value of compound $\mathrm{AC}-1$ was found to be 0.63 .

\section{Structure elucidation of compound 1}

The FTIR spectra showed sharp peaks at 2965.2 $\mathrm{cm}^{-1}$ and $2926.2 \mathrm{~cm}^{-1}$ indicating C-H stretching of alkanes.(7) Medium and weak peaks were observed at $1608 \mathrm{~cm}^{-1}$ and $1450 \mathrm{~cm}^{-1}$ indicating $\mathrm{C}=\mathrm{C}$ stretching of aromatic ring. Strong peak of 
ether (C-O stretching) was observed at 1050$1300 \mathrm{~cm}^{-1}$. Sharp peak of tetra substituted benzene ring was observed at $802 \mathrm{~cm}^{-1} .{ }^{1} \mathrm{H}$ NMR spectra confirmed two singlet aromatic protons $(\delta 6.85$ and 6.63), two olefinic protons $(\delta 6.50$ and 5.61), three methoxyl protons $(\delta 3.83,3.80$, and 3.77), and methyl protons $(\delta$ 1.87) indicating sixteen protons signals.

Mass spectra (FAB) confirmed a molecular peak at $m / z 208\left(\mathrm{M}^{+}\right)$. Fragment peaks were also observed at $193\left(\mathrm{M}^{+}-\mathrm{Me}\right)$ and $105\left(\mathrm{M}^{+}-\mathrm{C}_{6} \mathrm{H}_{5}+\mathrm{CO}\right)$. From the spectral data the structure of the compound $\mathrm{AC}-1$ was elucidated as $\beta$-asarone with molecular formula $\mathrm{C}_{12} \mathrm{H}_{16} \mathrm{O}_{3}$.

\section{Isolation of compound 2}

$1.5 \mathrm{~kg}$ dried rhizomes of Coleus forskohlii were defatted with petroleum ether at room temperature. The marc was then extracted with ethanol:water (60:40) twice. After $48 \mathrm{~h}$, the extract was filtered. The solvent was removed in vacuum. The residues ( $395 \mathrm{~g}$ ) were dissolved in $\mathrm{H}_{2} \mathrm{O}$. The aqueous solution was extracted with petroleum ether, $\mathrm{CHCl}_{3}$ and $n$-butanol, the $\mathrm{CHCl}_{3}$ extract was evaporated to give $85 \mathrm{~g}$ of residues. The residues were subjected to CC silica gel, eluted with petroleum ether-acetone (from petroleum ether to petroleum ether-acetone 1:1). The fractions were combined by monitoring with TLC to obtain fractions B $1 \sim \mathrm{B}$ 22.

The fraction B 8 (4 g) was chromatographed repeatedly on silica gel eluted with $\mathrm{CHCl}_{3}$ acetone and recrystallized from petroleum ether-acetone to afford $175 \mathrm{mg}$ of compound 2. The $R_{f}$ value of compound AC- 1 was found to be 0.48 .

\section{Structure elucidation of compound 2}

FTIR spectroscopy analysis were carried out to identify the constituents responsible for the antistress activity. Coleus forskohlii alcoholic extract shows absorption peaks located at $1035.71,1383.73$ and 1624.72 in the region $500-4000 \mathrm{~cm}^{-1}$.

The peaks corresponding to presence of fatty acids, carbonyl groups, flavanones and amide band of proteins. The ${ }^{1} \mathrm{H}$ NMR spectrum of compound 2 displayed a doublet of doublets centered at $3.35 \mathrm{ppm}(\mathrm{J} 9, \mathrm{~L} 1=10.00, \mathrm{~J} 9,8=5.00$ $\mathrm{Hz}$ ) for the $\mathrm{H}-9$ proton, and a doublet of doublets at $3.06 \mathrm{ppm}(\mathrm{J} 5,6,=10.00, \mathrm{~J} 5,6,=3.50 \mathrm{~Hz})$ for the ring junction proton. Forskolin with a massto-charge ratio of $411,393\left[\mathrm{MH}^{+}-\mathrm{H}_{2} \mathrm{O}\right], 375$ $\left[\mathrm{MH}^{+}-2 \mathrm{H}_{2} \mathrm{O}\right]$ and $315\left[\mathrm{MH}^{+}-2 \mathrm{H}_{2} \mathrm{O}-\mathrm{AcOH}\right]$.

\section{Test animals}

The experimental animals [Swiss albino mice (20-25 g) of either sex] were procured from the Animal House, Siddhartha Institute of Pharmacy, Babhnan, Gonda. The animals were given standard laboratory feed and water ad libitum. The experiments were performed between 8.00 am to $1.00 \mathrm{pm}$. The experiments were conducted in a sound proof laboratory. All the experimental procedures and protocols used in the study were reviewed by the Institutional Animal Ethics Committee.

\section{Assessment of antistress activity \\ Elevated plus maze test}

Anxiolytic activity was evaluated using the elevated plus maze. The elevated plus maze consisted of two open arms $(50 \times 10 \mathrm{~cm})$ crossed with two closed arms $(50 \times 10 \times 40 \mathrm{~cm})$. The arms were connected together with a central square $(10 \times 10 \mathrm{~cm})$. The apparatus was elevated to the height of $70 \mathrm{~cm}$ in a dimly illuminated room. Mice were divided into groups of six and received the compounds $\mathrm{C} 1$ and $\mathrm{C} 2$, the vehicle or the standard reference drug diazepam (2.0 $\mathrm{mg} / \mathrm{kg}$ i.p.). One hour post-administration, each rat was placed individually at the center of the elevated maze. The duration of the stay in open arm were noted.

\section{Forced swimming test}

The FST is the most widely used pharmacological in vivo model for assessing anti stress activity (Gupta et al 2010). The swimming test includes two exposures to a water tank, spaced 1 day apart. For these experiments, the tank sizes were $22 \mathrm{~cm}$ in diameter and $40 \mathrm{~cm}$ in height. The tank had a rounded lid and contained $20 \mathrm{~cm}$ high fresh water at $25^{\circ} \mathrm{C}$. During the first exposure, mice not yet treated were placed in the tank and left there for $15 \mathrm{~min}$. During the second exposure (test session), $30 \mathrm{~min}$ after the treatment, mice were placed in the tank and left there for 5 min during which their immobility time was observed. A mouse was considered immobile when it remained floating in the water, without struggling, making only very slight movements necessary to keep its head above the water.

\section{Treatment}

Animals were divided in to eight groups. Group I was control and was given normal saline in a dose of $10 \mathrm{ml} / \mathrm{kg}$ p.o. Group II was a positive control and was given standard drug, Diazepam 
$(2 \mathrm{mg} / \mathrm{kg}$, i.p.), suspended in the vehicle. Group III-V were treated as test groups and were given isolated Beta-asarone and Group VI-VIII were treated as isolated Forskolin at different doses viz. 50, 100 and $200 \mathrm{mg} / \mathrm{kg}$ respectively. All the test solutions, standard drug and control were administered orally 30 min prior to experiment.

\section{Statistical analysis}

The results are given as mean \pm SEM. The data obtained was analyzed by one-way analysis of variance (ANOVA) followed by Turkey's test. Differences were considered significant at the $5 \%$ level.

\section{RESULT}

\section{Elevated plus maze test}

Based on previous studies that were carried out on active constituents and in order to determine the effective dose on the EPM, Beta-asarone and Forskolin doses of 50, 100 and $200 \mathrm{mg} / \mathrm{kg}$ were tested. Mices exhibited decreased closed arm entries and increased time spent in the closed arm. Mice received the standard diazepam showed a significant $(\mathrm{P}<0.05) 311.5 \pm 5.36 \mathrm{sec}$ increase in the time spent in open arms in the dose of $2 \mathrm{mg} / \mathrm{kg}$, i.p. when compared to control. $\mathrm{C} 1$ and $\mathrm{C} 2$ significantly $(\mathrm{P}<0.05)$ increased the time spent in the open arms relative to the control at doses of 50, 100 and $200 \mathrm{mg} / \mathrm{kg}$. Result indicates in Table 1 that the most pronounced effect of $\mathrm{C} 1$ and $\mathrm{C} 2$ was produced at the dose of $200 \mathrm{mg} / \mathrm{kg}$. In this case, time spent of C1 and C2 in the open arms was $157.8 \pm 4.78 \mathrm{sec}$ and $152.5 \pm 1.87 \mathrm{sec}$ respectively compared to a value of $78.5 \pm 2.96 \mathrm{sec}$ for control. Moreover, both compounds $\mathrm{C} 1$ and $\mathrm{C} 2$ produce dose dependent activity.

Table 1. Effect of isolated compounds $\mathrm{C} 1$ and $\mathrm{C} 2$ at Elevated plus maze model

\begin{tabular}{|c|c|c|}
\hline \multirow{2}{*}{$\begin{array}{c}\text { Treatment } \\
\text { (dose: } \mathbf{~ m g} / \mathbf{k g})\end{array}$} & \multicolumn{2}{|c|}{$\begin{array}{c}\text { Time spent(s) } \\
\text { (mean+SEM) }\end{array}$} \\
\cline { 2 - 3 } & Open arm & Close arm \\
\hline Vehicle & $78.5 \pm 2.96$ & $211.2 \pm 7.42$ \\
\hline Diazepam & $311.5 \pm 5.36$ & $71.3 \pm 2.04$ \\
\hline C1(50) & $136.3 \pm 3.88$ & $164.7 \pm 7.35$ \\
\hline C1(100) & $151.5 \pm 3.40$ & $158.5 \pm 2.18$ \\
\hline C1(200) & $157.8 \pm 4.78$ & $160.2 \pm 5.16$ \\
\hline C2(50) & $129.8 \pm 2.12$ & $171.2 \pm 6.31$ \\
\hline C2(100) & $141.0 \pm 1.09$ & $154.7 \pm 3.32$ \\
\hline C2(200) & $152.5 \pm 1.87$ & $161.5 \pm 3.84$ \\
\hline
\end{tabular}

$\mathrm{n}=6$, the observation are mean $\pm \mathrm{SEM} * \mathrm{P}<0.05$, ANOVA followed by Dunnett's test, C1: Beta-asarone, C2: Forskolin

\section{Forced swimming test}

Table 2 shows the antistress effect of C1, C2 and diazepam in the experimental animals. The control animals remained immobile for most of the time during the test session. $\mathrm{C} 1$ and $\mathrm{C} 2$ (50, 100 and $200 \mathrm{mg} / \mathrm{kg}$, p.o.) induced a dosedependent significant reduction in the immobility time of rats $(\mathrm{P}<0.5)$ as compared to the control group. In the same experimental conditions, the antistress activity of the reference drug diazepam $(2 \mathrm{mg} / \mathrm{kg}$, i.p. $)$ was clearly evident $(\mathrm{P}<0.05)$. Antistress effect produced by $\mathrm{C} 1$ and $\mathrm{C} 2(200 \mathrm{mg} / \mathrm{kg}$, p.o.) was comparable to that of diazepam. This shows that $\mathrm{C} 1$ and $\mathrm{C} 2$ has significant antistress activity in a dose of $100 \mathrm{mg} / \mathrm{kg}$.

Table 2. Effect of isolated compounds $\mathrm{C} 1$ and $\mathrm{C} 2$ at Forced swimming test

\begin{tabular}{|c|c|}
\hline Treatment (Dose: $\mathbf{~ m g} / \mathbf{k g})$ & Survival time (s) \\
\hline vehicle & $184.1 \pm 0.22$ \\
\hline diazepam & $520.8 \pm 0.21$ \\
\hline C1 (50) & $195.3 \pm 0.31$ \\
\hline C1 (100) & $279.5 \pm 0.29$ \\
\hline C1 (200) & $289.7 \pm 0.37$ \\
\hline C2 (50) & $184.7 \pm 0.19$ \\
\hline C2 $(100)$ & $194.9 \pm 0.48$ \\
\hline C2 $(200)$ & $198.7 \pm 0.60$ \\
\hline
\end{tabular}

$n=6$, the observation are mean \pm SEM * $\mathrm{P}<0.05$, ANOVA followed by Dunnett's test, C1: Beta-asarone, C2: Forskolin 


\section{DISCUSSION}

In the search for new therapeutic products for the treatment of neurological disorders (like stress) and other conditions, global medicinal plants research has progressed constantly, demonstrating pharmacological effectiveness of different plant species in a variety of animal models (Shafeen et al 2012; Dahiya, 2007; Dahiya and Kaur, 2008). This is an important finding since herbal drugs are thought to be a good alternative or supplement in the therapy of stress disorders. However, it has to be borne in mind that there are not enough controlled double-blind clinical trials (Deng et al 2007). The isolated active compound $\beta$-asarone has been isolated previously by others from Acorus calamus but has not been evaluated antistress activity before (Graw et al 2002). Forskolin, a labdane diterpene is the main active ingredient in the ayurvedic herb Coleus forskohlii (Labatiae) that has been used in India since ancient times. The root portion of the plant has been traditionally used for medicinal purposes and contains the active constituent, Forskolin (Patel et al 2011). Beta-asarone and Forskolin isolated were analyzed and characterized by IR, NMR and MASS spectroscopy.

\section{REFERENCES}

Bharathi KN, Sivaramaiah N, Nagarjuna CG, Gupta A. Evaluation of antistress, anxiolytic and hypnotic activity of vedic calm, a polyherbal formulation. Pharmacogn. Mag. 2009;5(19):124-30. [DOI: 2009/5/19/124/59796]

Chandrashekhar R, Manohar VR, Rao SN. Acute anxiolytic activity of aqueous extract of Terminalia chebula fruit pulp in rats. Int. J. Res. Ayur. Pharm. 2013;4(1):112-5. [DOI: 10.7897/2277-4343.04138]

Dahiya R. Synthesis of a phenylalanine-rich peptide as potential anthelmintic and cytotoxic agent. Acta Pol. Pharm. 2007;64(6):509-16.

Dahiya R, Kaur K. Synthesis and pharmacological investigation of segetalin $\mathrm{C}$ as a novel antifungal and cytotoxic agent. Arzneimittelforschung 2008;58(1):29-34. [DOI: 10.1055/s-0031-1296463]

Dahiya R, Singh S. Synthesis, characterization and biological screening of diandrine A. Acta Pol. Pharm. 2017a;74(3):873-80.

Dahiya R, Singh S. Synthesis, characterization, and biological activity studies on fanlizhicyclopeptide A. Iran. J. Pharm. Res. 2017b;16(3):1176-84.

Dahiya R, Singh S. Toward the synthesis and pharmacological screening of a natural cycloheptapeptide of plant origin. Nat. Prod. Commun. 2017c;12(3):379-83.

Dahiya R, Singh S, Kaur K, Kaur R. Total synthesis of a natural cyclooligopeptide from fruits of sugar-apples. Bull. Pharm. Res. 2017;7(3):151. [DOI: 10.21276/bpr.201 7.7.3.4]

Dahiya R, Singh S, Varghese Gupta S, Sutariya VB, Bhatia D, Mourya R, Chennupati SV, Sharma A. First total synthesis and pharmacological potential of a plant based hexacyclopeptide. Iran. J. Pharm. Res. 2019;18(2):938-47.
In the Elevated plus maze (EPM) test, besides decreased open arm exploration, albino mice exhibited decreased closed arm entries and increased time spent in the closed arm. Mice received the standard diazepam showed a significant increase in the time spent in open arms when compared to normal.

This suggest decreased fear, an increased exploratory behavior and the behavioral disinhibitory effect of the standard antistress. Moreover, the extract produced dose dependent activity. All these results suggested that the extract possess antistress activity (Chandra shekhar et al 2013).

\section{CONCLUSION}

In conclusion, isolated compounds showed antistress activity in various acute stress models. The observed antistress activity is due to the prevention of desensitization of both the peripheral and central components of the hypothalamic-pitutary-adrenal axis (Bharathi et al 2009) and due to non-specifically increased resistance produced by the isolated compounds. This study provide significant evidence of the medicinal and traditional uses of Forskolin and Beta-asarone in stress disorder.

Deng S, West BJ, Palu AK, Zhou BN, Jensen CJ. Noni as an anxiolytic and sedative: A mechanism involving its gamma-aminobutyric acidergic effects. Phytomedicine 2007;14(7-8):517-22. [DOI:10.1016/j.phymed.2007.04.0 05]

Desai SK, Desai SM, Navdeep S, Arya P, Pooja T. Antistress activity of Boerhavia diffusa root extract and a polyherbal formulation containing Boerhavia diffusa using cold restraint stress model. Int. J. Pharm. Pharm. Sci. 2009;3(1):130-2.

Graw LJ, Jagar AK, Staden J. Isolation of Beta-asarone, an antibacterial and anthelmintic compound, from Acorus calamus in South Africa. S. Afr. J. Bot. 2002;68(1):31-5. [DOI: 10.1016/S0254-6299(16)30450-1]

Gupta V, Bansal P, Kumar P, Shri R. Anxiolytic and antidepressant activities of different extracts from Citrus paradisi var. duncan. Asian J. Pharm. Clin. Res. 2010; 3(2):98-100.

Khatun S, Chatterjee NC, Cakilcioglu U. The strategies for production of Forskolin vis-a-vis protection against soil borne diseases of the potential herb Coleus forskohlii Briq. Eur. J. Med. Plants 2011;1(1):1-9. [DOI: 10.9734/EJMP/ 2011/128]

Oloke J, Odelade K, Oladeji 0 . Characterization and antimicrobial analysis of flavonoids in Vernonia amygdalina : A common chewing stick in South-Western Nigeria. Bull. Pharm. Res. 2017;7(3):149. [DOI: 10.21276/ bpr.2017.7.3.2]

Patel NB, Galani VJ, Patel BJ. Antistress activity of Argyreia speciosa roots in experimental animals. J. Ayurveda Integr. Med. 2011; 2(3):129-36. [DOI: 10.4103/0975-9476.85 551] 
Senthil Kumar R, Vinoth Kumar S, Sudhakar P. Anticancer activity of methanolic leaf extract of Morinda tinctoria roxb. against ehrlich ascites carcinoma in mice. Bull. Pharm. Res. 2017;7(2):146.

Shafeen S, Reddy ST, Arafath S, Nagarjuna S, Reddy PY. Evaluation of antianxiety and antidepressant activity of Cassia occidentalis leaves. Asian J. Pharm. Clin. Res. 2012; 5(3):47-50

Shenvi S, Hegde VR, Kush A, Reddy GC. A unique water soluble formulation of $\beta$-asarone from sweet flag (Acorus calamus L.) and its in vitro activity against some fungal plant pathogens. J. Med. Plants Res. 2011;5(20):5132-7.

Singh AK, Dhamanigi SS, Asad M. Anti-stress activity of hydro-alcoholic extract of Eugenia caryophyllus buds (clove). Indian J. Pharmacol. 2009;41(1):28-31.

Tiwari N, Chaudhary A, Mishra A, Bhatt G. Antimicrobial activity of $\beta$-asarone from Acorus calamus leaves. Int. J. Chem. Anal. Sci. 2010;1(9):211-3.

Viana CB, Carbonezi LH, Martins RCC. Isolation of pentacyclic triterpenes from Simira sampaioana (standl.) steyerm (rubiaceae) as possible anticancer agents. Bull. Pharm. Res. 2017;7(1):142. [DOI: 10.21276/bpr.2017.7.1.5] 